\title{
The mechanical effects of bulges developed around bark-included branch junctions of hazel (Corylus avellana L.) and other trees
}

\author{
Duncan Slater ${ }^{1} \mathbb{D}$
}

Received: 11 August 2020 / Accepted: 16 October 2020 / Published online: 23 January 2021

(c) The Author(s) 2021

\begin{abstract}
Key message Large bulges formed around bark-included branch junctions can be conceived of as 'compensatory growth'. Despite Claus Mattheck's hypothesis that 'the larger the bulges, the more likely the branch junction is to fail', this study identifies that the extent of the defect inside such bulges is key information in predicting the junction's load-bearing capacity.

Abstract A currently prevalent rule in European arboriculture is that if a bark-included branch junction in a tree is associated with a large bulge in-line with the plane of the included bark then it is more likely to fail than if there is a smaller bulge or the absence of bulging. This rule for arborists originates from an initial suggestion with no associated data and is not logically consistent with recent research into the effects of natural bracing in trees, nor guidance provided by the International Society of Arboriculture. This also raises the question of how to correctly interpret the function of these bulges formed at bark-included junctions: either as secondary growth that has been pushed to the side by internal growth pressures, or as compensatory growth developing around a weakened component. To test the veracity of this rule, 117 branch junctions of common hazel (Corylus avellana L.) were subjected to tensile tests, comprising of controls with no bark included within them and bark-included specimens exhibiting a range of bulge sizes. In addition, photographs from the failure of 110 barkincluded junctions were categorized to assess the frequency of failed specimens with different degrees of bulging. The results of the mechanical testing identified three significant factors that affected the maximal bending moment of these branch junctions: their categorized morphology, the diameter ratio of the branch junction and the width of the included bark at the apex of the junction. Overall, and in each category of branch junction tested, the extent of bulging was not found to be a significant predictor of the junctions' maximal bending moment. This finding was reinforced by the analysis of the images of bark inclusion failure where the most frequent bark inclusions to fail were those associated with little to no bulging. Both findings identify that the bulging would be better interpreted as compensatory growth. This study highlights the need for further research on the load-bearing capacity of bark-included branch junctions to better inform arborists and tree managers as substantial variations in their biomechanical performance have not yet been elucidated.
\end{abstract}

Keywords Axillary wood $\cdot$ Branch junction $\cdot$ Corylus avellana $\cdot$ Included bark $\cdot$ Natural bracing $\cdot$ Tensile tests

\section{Introduction}

Many urban trees must undergo regular checks by arborists to ensure that they do not present unnecessarily high risks to persons or property in the location in which they are growing

Communicated by Speck.

Duncan Slater

dslater@myerscough.ac.uk

1 Greenspace Department, University Centre Myerscough, St. Michaels Road, Bilsborrow, Preston PR3 0RY, UK
(Lonsdale 1999). The sophistication of tree risk management techniques is ever-increasing (Dunster et al. 2017) but there is still much guidance provided to arborists that has not been verified by scientific studies of tree structure and function.

A commonly encountered defect of the aerial structure of trees is where bark has become included within a branch junction in a tree (Matheny and Clark 1994; Smiley 2003; Slater 2018a). Substantial inclusions of bark into junctions are typically observable by arborists during a tree assessment due to malformation of the junction's bark ridge, visible bark-to-bark contact at the junction, water runs emanating from the junctions and often associated bulging at such junctions (Dunster et al. 2017). 
A current prevalent theory in Europe is that the failure of these bark-included branch junctions is inevitable due to internal growth pressures building up within them as they develop (Mattheck and Vorberg 1991; Mattheck and Breloer 1994). Mattheck's hypothesis states that when internal growth pressures within a branch junction are high, secondary growth is "pushed out" to develop at the sides of the junction. This "pushing" is considered by Mattheck (1998) as the cause of prominent bulges of xylem (often informally referred to as 'ears') at the edges of and in the plane of the included bark. Such bulged branch junctions (Fig. 1), due to Mattheck's hypothesis, have been considered more vulnerable to failure than other morphological forms of bark inclusions (Mattheck and Breloer 1994). Consequently, many trees have been braced, felled or heavily pruned on that basis by European arborists. This theory contrasts with the advice given by the International Society of Arboriculture (ISA) that "a bulge is caused by new tissue formed as a response to movement. The additional wood that is formed reinforces the wood structure at the weak area" (Dunster et al. 2017). This raises the question as to whether this bulging is always a sign of a developing weakness at a junction-or whether the bulging should be interpreted as having the function of compensatory growth around a previously weaker branch junction.

The wood formed centrally in the axil of a normally formed branch junction (referred to hereafter as 'axillary wood') has been shown by many authors to have a higher wood density and contain complex wood grain patterns, including whorled grain (Shigo 1985; Hejnowicz and Kurcryńska 1987; Lev-Yadun and Aloni 1990; Kramer 1999; André 2000; Kramer and Borkowski 2004; Slater et al. 2014). This wood also exhibits a highly restricted sap flow rate (Larson and Isebrands 1978; Zimmermann 1978; Shigo 1985), suggesting this is an example of "trade-off" in these xylem tissues between mechanical strength and sap conductance efficiency (Gartner 1995). Axillary wood has been shown to be an important strengthening component in normally formed branch junctions (Slater and Ennos 2013) and failure to form axillary wood can lead to the inclusion of bark within the branch junction, weakening it substantially. Slater and Ennos (2015b) tested the wood formed in bulges either side of bark inclusions in the branch junctions of common hazel (Corylus avellana L.) finding that it had intermediate tensile strength and wood density when compared to axillary wood and the wood from adjacent stems. Slater (2016) describes a category of bark inclusion where bulging either side of the included bark has resulted in a cuplike structure, naming that form of branch junction a 'cup union' (Fig. 2a). Such cup-shaped unions are a frequentlyencountered type of bark-included branch junction in trees and have been proven to be a stronger form of bark-included branch junction in common hazel than those with a wide area of included bark at the apex of the join and little bulging (Fig. 2b), ceteris paribus (Slater and Ennos 2015a). That the forming of a cup union through the growth of bulges leads to the development of a stronger junction does not fit with Mattheck's hypothesis that increased bulging is a sign of greater weakness.

Recent research has identified a strong association between the presence of 'natural braces' and bark being included within branch junctions in trees (Slater 2018a). A 'natural brace' is a configuration in the crown of a tree (for example, crossing branches or entwining branches) that
Fig. 1 A bark-included branch junction in silver birch (Betula pendula Roth.) exhibiting considerable bulging at this bifurcation. a View of the bulging in-line with the bifurcation. b View of the bulging perpendicular to the bifurcation

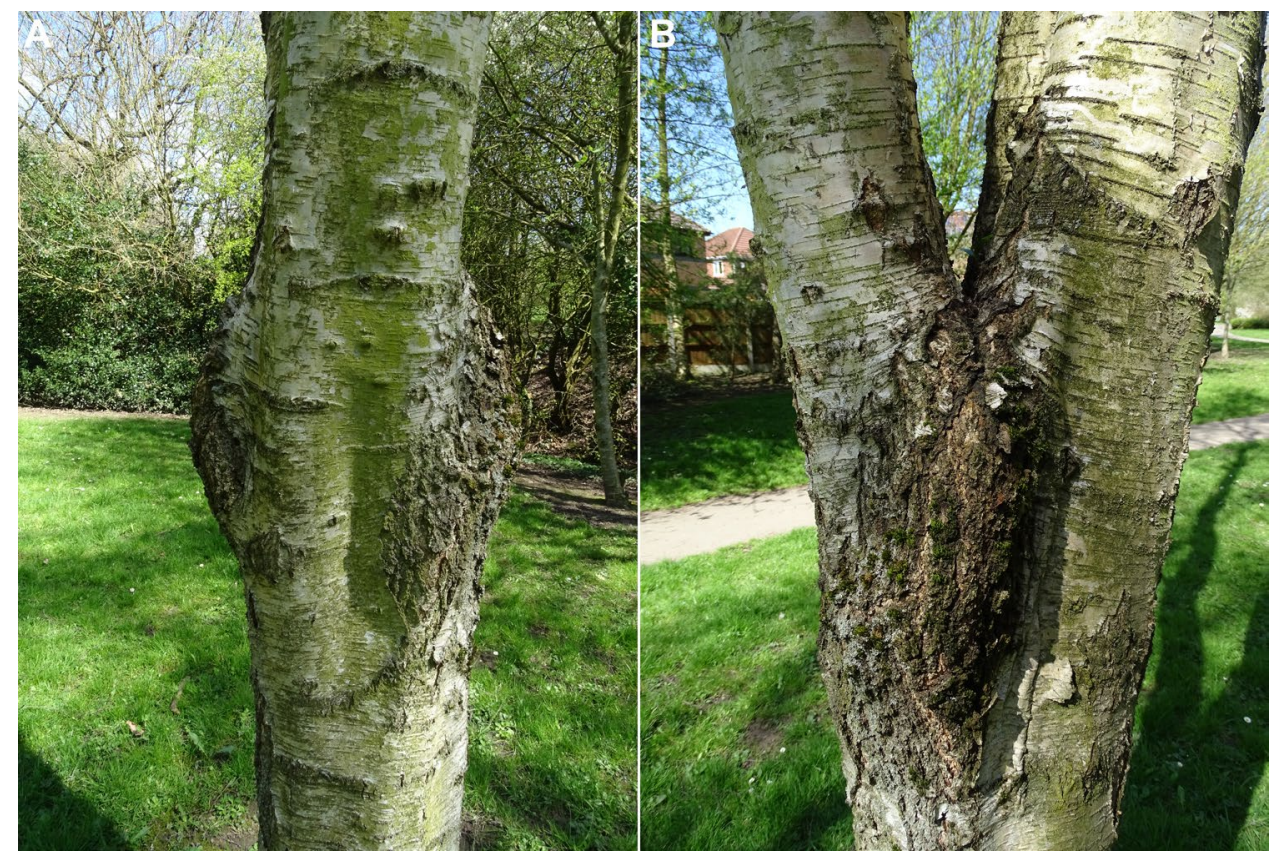



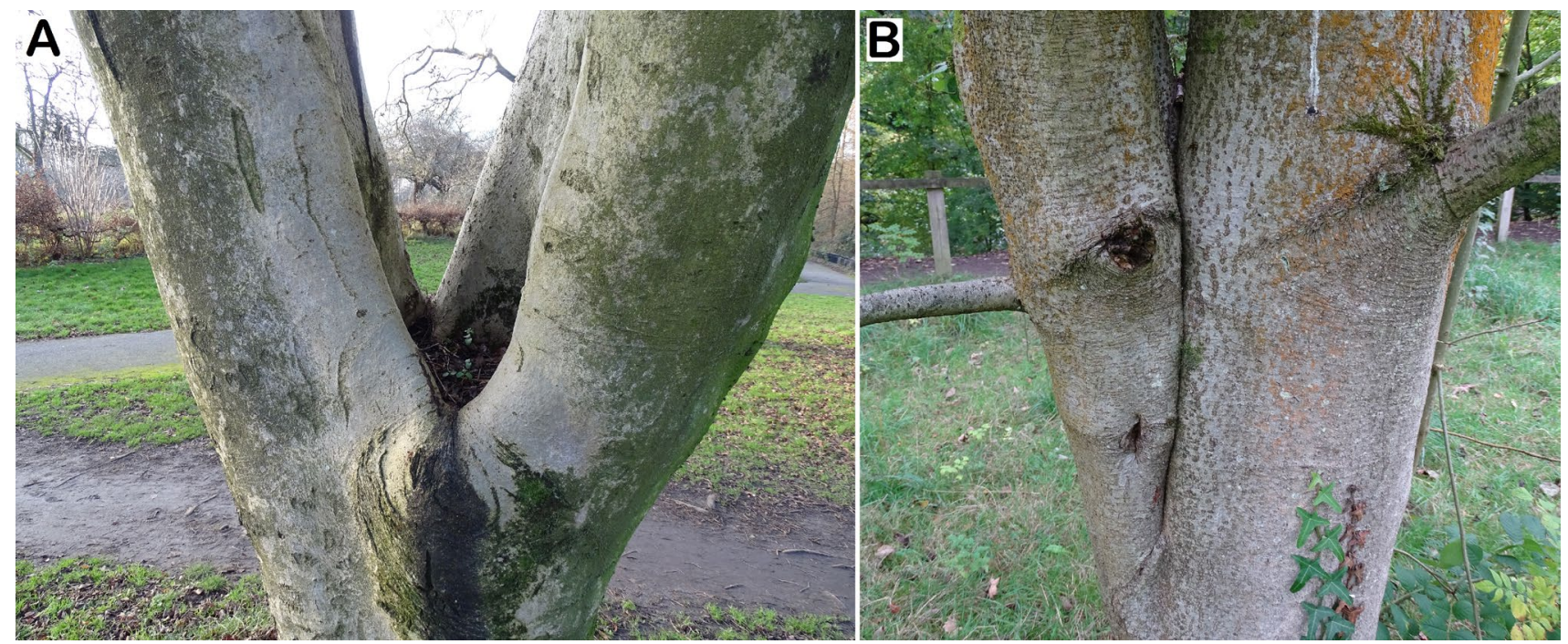

Fig. 2 a Bark-included branch junction in manna ash (Fraxinus ornus L.) which has bulges either side of the junction that cause the overall shape of the junction to become cup-shaped, making it able to hold

prevents normal mechanical loading to the branch junction set below it. Slater (2018b) highlights that the growth of a bulge at a branch junction is most often associated with that junction being released from natural bracing and thus experiencing much more dynamic movement and mechanical loading. Figure 3 shows an example of a naturally braced junction being released from a natural brace and subsequent changes in the junction's morphology: Stage 1: A lateral branch, acting as a natural brace, substantially reduces loading to the branch junction set below it, resulting in the formation of a bark-included junction. Stage 2: The natural brace is lost due to pruning or death of the bracing branch-the branch junction now receives 'normal' loading and is subject to substantially more dynamic movement. The junction will be most vulnerable to failure at this stage. Stage 3: Over successive years, if the branch junction does not fail mechanically, additional wood is added to the branch junction in the form of 'bulges' either side of the included bark due to the new regime of much higher mechanical stimulation (thigmomorphogenesis). The forming and growth of these bulges can be interpreted as compensatory growth. Stage 4: Years of secondary growth at the branch junction typically leads to the formation of a cup union (Fig. 2), although, in a young tree, the included bark may become fully embedded in the compensatory growth. At this final stage, if it is reached, the load-bearing capacity of the branch junction achieves a good match for the loading it is receiving annually, despite the presence of included bark within it.

Consequently, under this alternative theory, the bulging has a functional strengthening role for a previously weakened component and it is being formed in response water or organic detritus within it. b Bark-included branch junction in common alder (Alnus glutinosa (L.) Gaertn.) with a long seam of included bark evident and little to no associated bulging

to mechanical perturbation, not due to internal growth pressures.

In terms of logic, if the main stem of a tree secondarily thickens and increases its diameter, its maximal bending moment before failure also increases (Niklas and Spatz 2012). The same is the case for the tree's branches and its roots. Why would a branch junction in a tree be different? Why would a branch junction become weaker if more wood is being added to it through the process of secondary thickening? The growth of a bulge around a bark inclusion may be the result of many years of secondary growth (Figs. 1 and 2) or that bulge may only have recently developed at the branch junction. Figure 4 illustrates the development of a bulge at a bark-included junction over an eleven-year period. When evaluating Mattheck's hypothesis that the secondary growth is being pushed to the side of the bark inclusion, one should consider that the whole of the bulge formed on the outside of the junction is sheathed by cambial tissues: would any growth pressures pressing the two branches together within the junction have such a direct effect on the growth of the vascular cambium at the outer edge of the bulge in Fig. 4 when it is offset to this extent? In terms of structure and function, it is important to resolve, through testing, whether this change in form represents an improvement in the junction's load-bearing capacity or whether the junction is weakening as the bulge increases in size.

Bulges at a branch junctions may be forming around a large defect over the last one or two growing seasons or it may have formed for many years in compensation for a small defect. Logically, this suggests that the extent of bulging around a bark-included branch junction may not, as a single factor, be a strong predictor of its maximal 


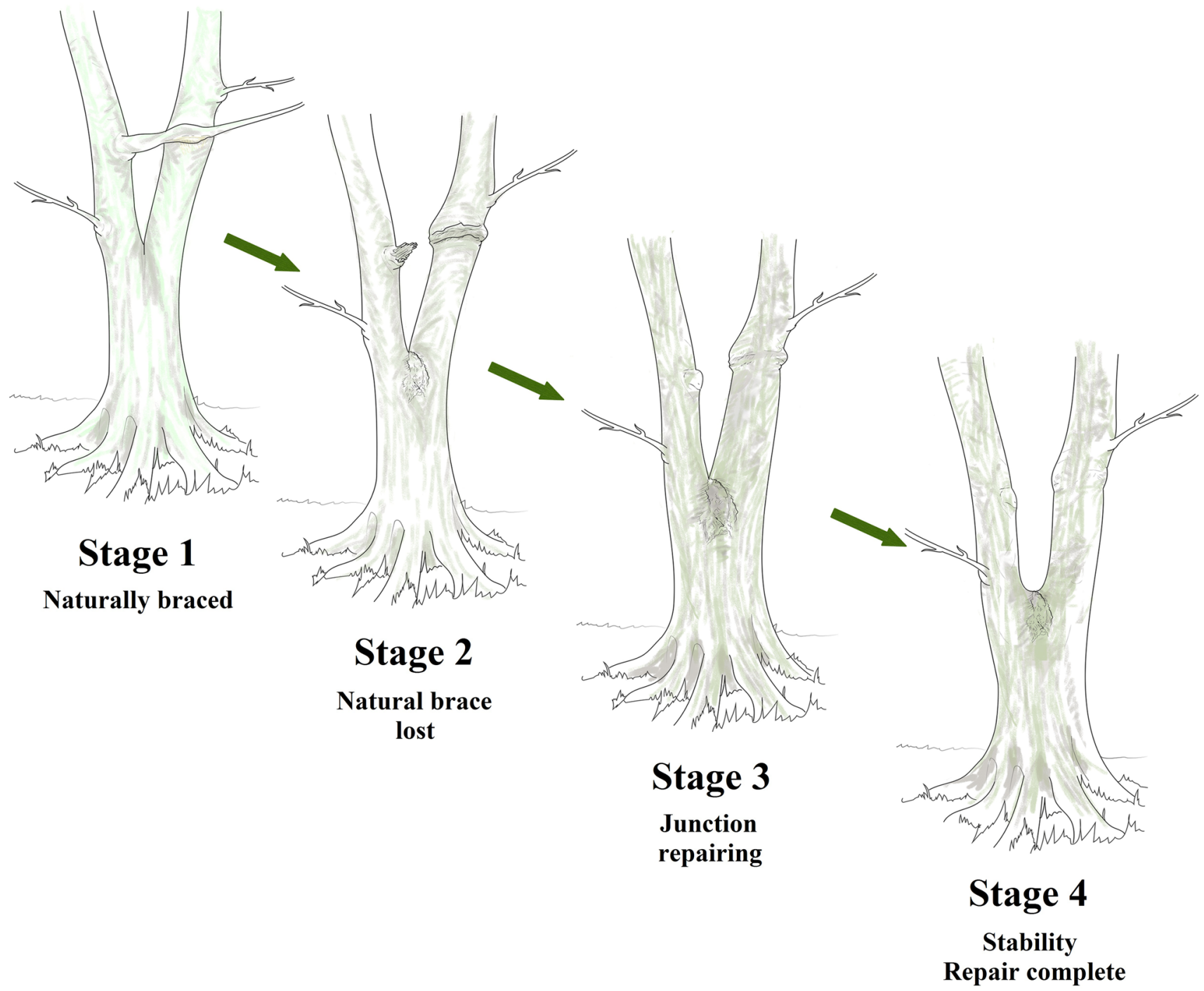

Fig. 3 A common sequence of changes to a naturally braced branch junction, as observed by Slater (2018a)

bending moment, as the load-bearing capacity of such a branch junction is likely to be at least partly dependent on what material lies within the bulged junction (i.e. how much of the join between the two branches is defective due to the presence of the included bark).

Other factors affect the mode of failure and relative bending strength of branch junctions. The ratio in diameter of the two co-joined branches is known to affect the mode of failure (Gilman 2003; Kane et al. 2008; Slater and Ennos 2013) and thus the relative bending strength of branch junctions, so this factor is likely to be needed in any modelling of the biomechanical performance of branch junctions. Heightened wood density can also confer greater strength to a component part of a tree (Anten and Schieving 2010) and axillary wood has previously been shown to have a much higher density than surrounding xylem tissues (Slater and Ennos 2015b).

This introduction describes two diametrically opposed theories on the cause and function of bulges formed at bark-included branch junctions. To seek to resolve this dichotomy, this study investigated branch junctions with different extents of bulging to determine its effect on maximal bending moment through static testing. Photographs of previous bark-included branch junction failures were also used to determine if the failure of bark-included junctions with larger bulges in standing trees was more frequent than those with little or no bulging evident. If Mattheck's hypothesis is correct, then the failure of substantially bulged branch junctions could be expected to be more frequent than the failure of less bulged or non-bulged 


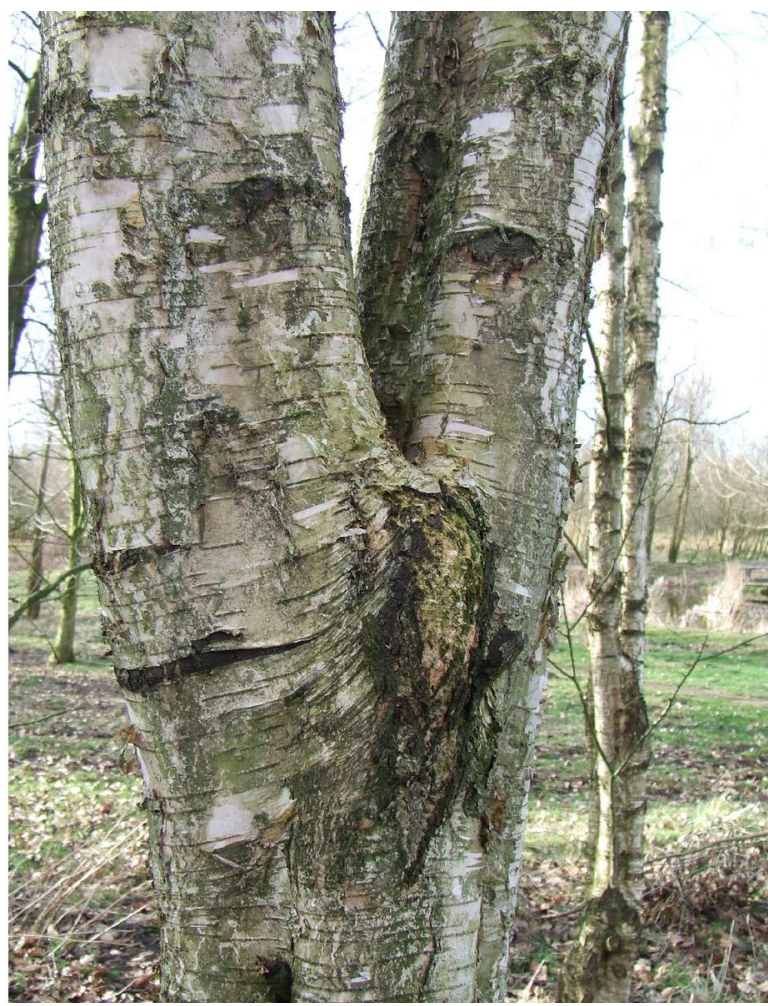

Fig. 4 Two sequential digital photographs of the development of a bulge at a bark-included junction in a silver birch (Betula pendula Roth.) in the absence of any natural bracing. Over the 11 years of this time-lapsed image, the bulge has increased more in height than in

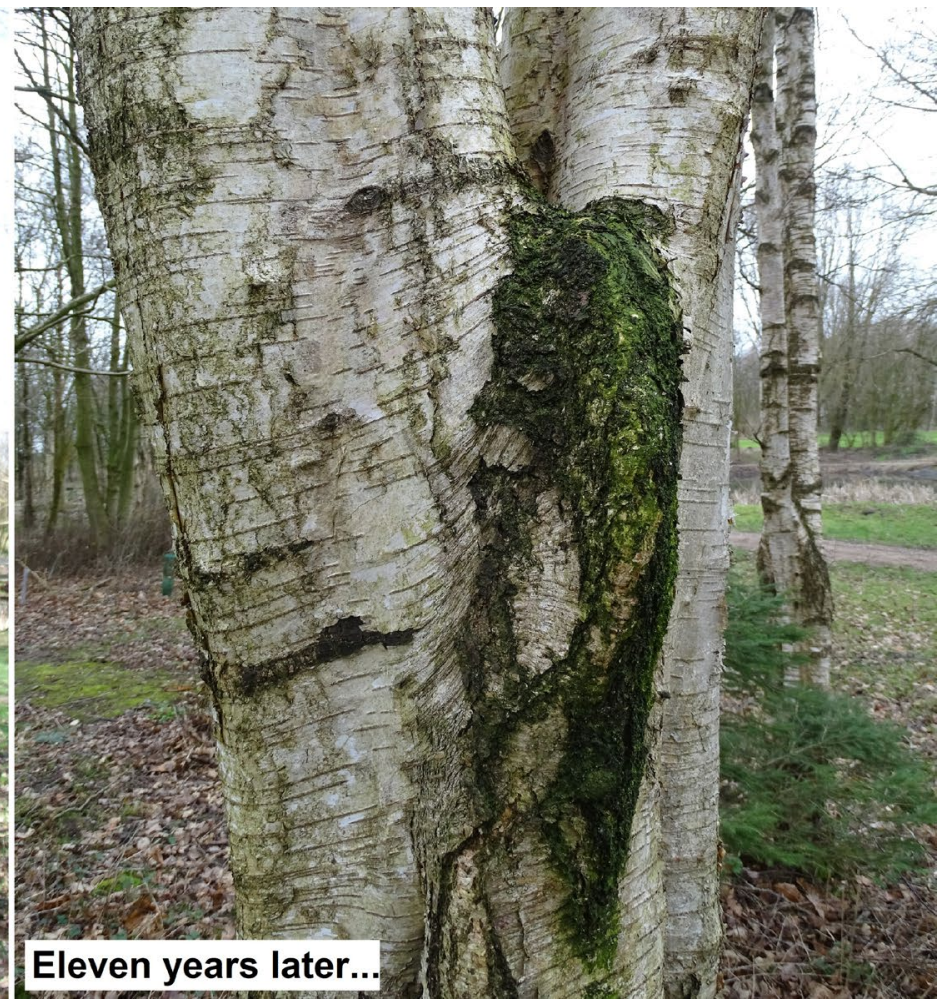

diameter and the junction has changed type from a wide bark inclusion to a cup union. The bark markings on the stems of the birch help to identify that the bulge has grown such that its apex is now approximately $210 \mathrm{~mm}$ higher in the second image specimens, subject to the frequency of occurrence of these different forms of branch junction in a tree population.

The following hypotheses were set for this study:

$H_{1}$ Cup unions will have a higher mean peak bending moment than wide bark inclusions (Slater and Ennos 2015a).

$\mathrm{H}_{2}$ The peak bending moment of a bark-included branch junction will decrease in association with an increase in the size of the bulge around the included bark (supporting Mattheck's hypothesis).

$\mathrm{H}_{3}$ Wood density will be higher at the apex of the branch junctions than in adjacent xylem tissues (Slater and Ennos 2015b).

$\mathrm{H}_{4}$ Analysis of a record of failed bark-included junctions will show that those with larger bulges have failed more frequently (supporting Mattheck's hypothesis).

\section{Materials and methods}

\section{Sample collection}

On 11 January 2019, 118 branch junctions of hazel, each approximately $450 \mathrm{~mm}$ in length, were cut from a hazel coppice in Prestwich Country Park, Manchester. Each branch junction had two arising branches of similar diameter (i.e. they were all bifurcations) and the parent stems were three-to-10 years old. Specimen selection was based on obtaining approximately 40 control specimens (normally formed branch junctions), 40 bark-included specimens exhibiting only minor bulging and 40 further barkincluded specimens that exhibited more noticeable degrees of bulging. No more than two specimens were taken from any one hazel tree. Each specimen was cut so that the length of the parent stem retained was at least twice the length of the visible branch bark ridge and each arising branch was at least $220 \mathrm{~mm}$ in length. The mean diameter of the parent stem for the specimens collected was $36.15 \mathrm{~mm} \pm 8.37$ Standard Deviation (SD). Each specimen 
was wrapped within a plastic bag to prevent moisture loss and kept in a cold store until being tested within $48 \mathrm{~h}$.

Hazel has been a species subject to a significant range of testing for the strength and anatomy of its branch junctions (Pfisterer 2003; Slater and Ennos 2013, 2015a, b, 2016; Slater et al. 2014; Ozden et al. 2017), to which this study contributes further.

\section{Tensile testing}

The procedure to prepare the branch junctions for tensile testing was the same as reported in Slater and Ennos (2013). Each branch junction had two $6 \mathrm{~mm}$ diameter holes drilled approximately $200 \mathrm{~mm}$ from the top of the branch bark ridge of the fork, one hole through the middle of each branch near its distal end. The drill holes were set perpendicular to the plane of the bifurcation (Fig. 5c). Excess branch length above these drill holes was cut away.

The over-bark diameters of the parent stem and the basal diameters of the two arising branches were measured using digital callipers, both in the plane and perpendicular to the plane of the bifurcation (Fig. 5a). The distances between the two drill holes and the top of the junction's bark ridge of the branch junction were measured using an engineer's scale ruler to give the distances $A B, A C$ and $B C$ (Fig. $5 \mathrm{c}$ ).

The diameter ratio of the junction was defined as the basal diameter of the smaller-diameter branch divided by the basal diameter of the larger-diameter branch, given as a percentage. The widest point of bulging at the branch junction was also measured $(W)$ and a 'bulge ratio' was calculated by dividing the difference between the bulge diameter $(W)$ and the parent stem diameter $\left(\mathrm{PS}_{2}\right)$ by the diameter of the parent $\left(\mathrm{PS}_{2}\right)$, with this ratio reported as a percentage.

Each specimen was then attached between the crosshead and the base of an Instron ${ }^{\circledR} 3369$ universal testing machine, using two purpose-made steel ' $U$ ' shape brackets. A $5 \mathrm{~mm}$ bolt held each arising branch within the centre of one ' $U$ ' bracket, using the pre-drilled holes (Fig. 5d). The crosshead of the Instron ${ }^{\circledR}$ testing machine was then moved upwards at a rate of $35 \mathrm{~mm} \mathrm{~min}^{-1}$, pulling the branch junction apart, while the force required was measured with a $50 \mathrm{kN}$ load cell and an interfaced computer plotted a graph of force against displacement.
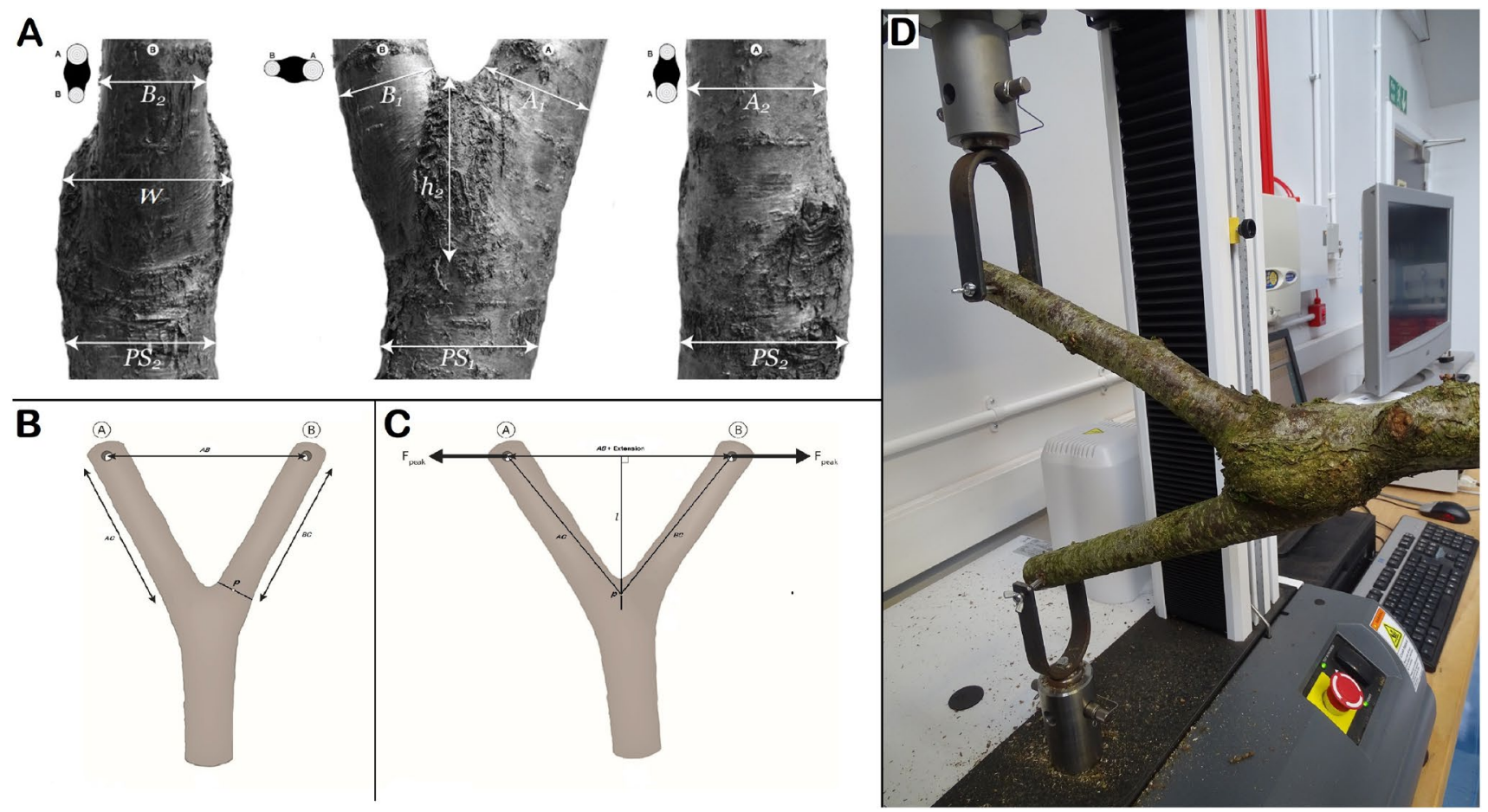

Fig. 5 a Measurements taken for all branch junctions subjected to tensile testing: the diameters of the parent stem perpendicular to the bifurcation ( $\left.\mathrm{PS}_{1}\right)$ and in-line with the bifurcation $\left(\mathrm{PS}_{2}\right)$; the diameters of both branches arising from the junction, coding the larger-diameter branch as ' $A$ ' and smaller-diameter branch as ' $B$ ', measuring their diameters both perpendicular to the bifurcation $\left(A_{1}\right.$ and $\left.B_{1}\right)$ and inline with the bifurcation $\left(A_{2}\right.$ and $\left.B_{2}\right)$; the length of the branch bark ridge externally, over-bark $\left(h_{2}\right)$; and the largest diameter of the bulged section of the branch junction $(W)$. b The standard method used by previous researchers to calculate the peak bending stresses at a branch junction. c A revised method used in this study, setting the pivot point (p) within the branch junction by a distance equivalent to half the diameter of the smaller branch $\left(B_{1} / 2\right)$. d Photograph of a bulged branch junction specimen mounted to the testing machine using steel U-shaped brackets and bolts through the drilled ends of both arising branches of the branch junction 
The peak force, the extent of displacement at peak force and the mode of failure for each branch junction were recorded. The modes of failure were categorised as described in Slater and Ennos (2013) into Type I (compression failure on the outer edge of the smaller-diameter branch B prior to tensile failure at the branch junction), Type II (tensile failure at the branch junction with no observed compression of branch tissues) and branch failures (where failure is in the smaller-diameter branch (Branch B, Fig. 5c), not at the junction being tested).

After this mechanical testing, the fracture surfaces of any branch junctions exhibiting included bark were photographed using a mounted digital camera to allow analysis of the included bark's proportion and position within the branch junction. The images were analysed using ImageJ to measure the proportion of bark at the apex of the branch junctions to determine if this was a predictive factor for the branch junctions' maximal bending moments (Fig. 6).

\section{Modelling load-bearing capacity}

Many previous studies have calculated the bending stresses at mechanically tested branch junctions using a simple beam theory method based on the leverage being applied to the section modulus of the smaller branch at its base (e.g. Gilman 2003; Kane 2007; Kane et al. 2008; Slater and

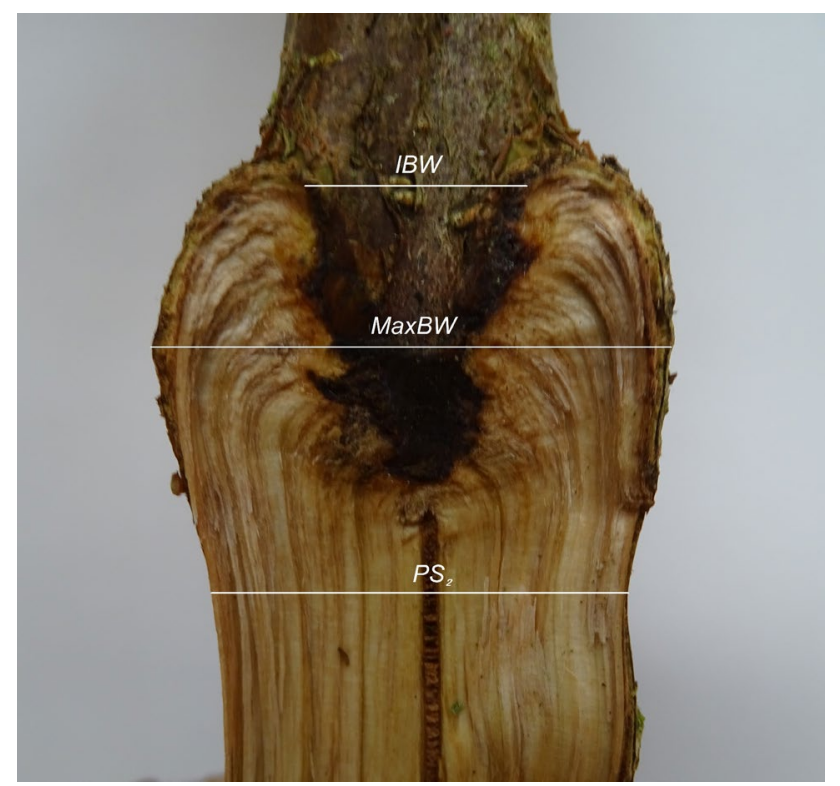

Fig. 6 Measurements taken of the tested bark-included junctions recorded by digital photography, using ImageJ to analyse the fracture surfaces: IBW is the included bark's width at the apex of the branch junction, MaxBW is the width of the bulge at its largest diameter (equivalent to the parameter $W$ measured externally with digital callipers) and $\mathrm{PS}_{2}$ is the diameter of the parent stem measured below the point where the pith bifurcates within the branch junction
Ennos 2013), as illustrated in Fig. 5b. This method sets the pivot point $(p)$ at the base of the smaller-diameter branch $(B)$, using the section modulus of the cross-section of that branch at that point to calculate the bending stresses at the outer edges of the branch, as a proxy for the stresses acting at the branch junction. However, it is now recognised that this method of calculation does not accurately represent the pivot point $(p)$ for the lever arm used in these experiments, leading to an under-estimation of the load-bearing capacity of such branch junctions (Slater and Ennos 2013; Meadows and Slater 2019). Figure 5c illustrates a pivot point ( $p)$ and lever arm $(l)$ that are more relevant to calculating bending stresses when pulling apart a Y-shaped branch junction. The lever arm is extended by half the diameter of branch $B\left(B_{1} / 2\right)$ in this latter calculation. Note that the plane of the section modulus around the pivot point is orientated differently from the one used in $5 \mathrm{~B}$, which affects the calculation of peak moment $\left(M_{\text {peak }}\right)$.

The maximal bending moment, $M_{\text {peak }}$, required to break each fork was calculated using the equation:

$M_{\text {peak }}=F_{\text {peak }} l$,

where $F_{\text {peak }}$ is the peak force recorded by the interfacing computer during the tensile testing and $l$ is the lever arm length, calculated when the peak force was applied using Pythagoras's theorem, as the adjacent side of a right angled triangle, taking the measurement $b c_{2}$ as the hypotenuse and half the length of $a b$ plus half the recorded displacement at peak force as the opposite side (Fig. 5c).

As the section modulus of the section being pivoted within the branch junction could not be accurately estimated, analysis using calculations of the maximal bending stress for each junction was considered an unsuitable approach. Instead, the specimens were normalised for their differences in size by comparing the log of the parent stem diameter (taking a weighted average of $\left(\left(\mathrm{PS}_{1}+\mathrm{PS}_{1}+\mathrm{PS}_{2}\right) / 3\right)$ with the $\log$ of the maximal bending moment $\left(M_{\text {peak }}\right)$. This approach then allowed analysis of variance in bending moment for the factors of diameter ratio, junction type and bulging ratio.

The size of the sample deemed suitable for full data analysis of their mechanical properties was reduced from the 118 branch junctions originally collected to 115 , as one control specimen was too large in diameter to fit within the bespoke $U$-shaped brackets, one specimen failed along the length of its smaller branch rather than at the branch junction and one bark-included specimen contained a crack around which two bulges of wood had formed. A proportion of the control specimens contained small amounts of embedded bark, so those specimens were then analysed as a different 
group, assuming the embedded bark may have compromised their load-bearing capacity to some extent.

These changes resulted in the distribution of tested branch junctions across the following groups: 22 control specimens; 14 specimens with embedded bark; 49 specimens that were categorised as cup unions; and 30 specimens that were categorised as wide bark inclusions.

\section{Wood density testing}

Wood density testing was carried out on the xylem tissues of the stem of each successfully tested specimen, contrasting these tissues with a sample obtained from within the axil of each branch junction. A heightened wood density in any of the bulges would imply the presence of axillary wood. These two cuboid samples of approximately $22 \mathrm{~mm}^{3}$ in volume were cut from each specimen using a pull-saw and sharp blade. The samples were dried in an oven at $60{ }^{\circ} \mathrm{C}$ for 7 days and then the weight of each cuboid was measured on a laboratory weighing scales. The volume of each cuboid was determined by the water displacement method (Hughes 2005). By dividing the sample's dried weight by the sample's volume when dried, the wood dry density for each cuboid was calculated.

\section{Photo analysis of failed bark-included junctions}

As the tested branch junctions were juvenile specimens, the testing described above is only approximately representing modelling of the effect of bulging on the maximal bending moment of more mature branch junctions. Consequentially, it was determined to complement the study by analysing photographs of failed bark-included branch junctions in mature trees. A collection of 110 digital photographs of the fracture surfaces of failed bark-included branch junctions was used for this purpose. These images had been collected over a period of 12 years by the author, recording every such failure found on visits to woods, gardens, parks and parkland in the UK, USA and Canada. Slater (2018a) reported a ratio of 21:78 of bark-included junctions with a bulge ratio of $10 \%$ or more to those with a lower bulge ratio (in the absence of natural braces) in a large-scale cohort study of a mix of tree species, so this ratio was used to inform this comparison of failure rates in association with bulging ratio.

The photographs of the 110 failed bark-included branch junctions were measured using ImageJ to determine the extent of their bulging when compared with the diameter of the stem set below the failed branch junction. These images represented 22 genera: 3e genera of gymnosperms (Pinus, Taxodium and Thuja) and 19 genera of angiosperms, with multiple images of such failures in the genera Acer, Betula, Fagus, Fraxinus, Quercus, Populus, Prunus and Salix. The extent of the bulge was taken as the widest diameter across the fracture surface of the failed branch junction where included bark was visible (Fig. 7). Using the methodology described, some failures exhibited a negative value for the bulge ratio, as seen in Fig. 7b-i.e. the maximum width of the section related to the bark inclusion $(W)$ was less than the width of the parent stem $\left(\mathrm{PS}_{2}\right)$ due to the narrowing arc-shape of the upper part of the branch junction and the absence of any visible bulging around the included bark. The ratio of the bulge diameter to the stem diameter (the "bulge ratio', calculated in the same way as with the mechanically tested specimens) was then used to assess the frequency of these branch junction failures at different ratios by grouping specimens around 5\% intervals. Given the differing heights above ground of the images taken and the inevitable distortions caused by the curvature of a camera lens, the bulge ratio calculated for each photograph can only be considered an approximation of the empirical difference in these two diameter measurements, so only broad categorisation was considered valid.

\section{Statistical analysis}

Statistical analysis was undertaken using the software packages Minitab v. 19 and Excel 2016.

The equation defining a linear relationship between the $\log$ of the specimens' parent stems and the log of the maximal bending moment of each specimen was used to normalise the bending moment for the geometrical scale of each branch junction, so it was possible to analyse the effects of the factors of diameter ratio, junction type, bulging ratio and the length of bark at the apex of the bark-included junctions.

One-way ANOVAs were used to analyse the differences in group means within the samples under tensile testing, the normality of the residuals was verified using an Anderson-Darling test and post hoc Tukey test were used to identify differences between sample means at the 5\% significance level. Differences in wood density between the junction apices and adjacent stem tissues were analysed using a paired $\mathrm{t}$ test. Bivariate regression was used to model the maximal bending moment of bark-included branch junctions, determining the combination of measured parameters that had the greatest predictive power, whilst using Minitab's Goodnessof-Fit function to determine if any factor added or detracted from the model's effectiveness.

\section{Results}

\section{Tensile tests of branch junctions}

There was a strong positive correlation between the log of the specimens' parent stem diameters and the log of the maximal bending moment of each specimen (Fig. 8). 


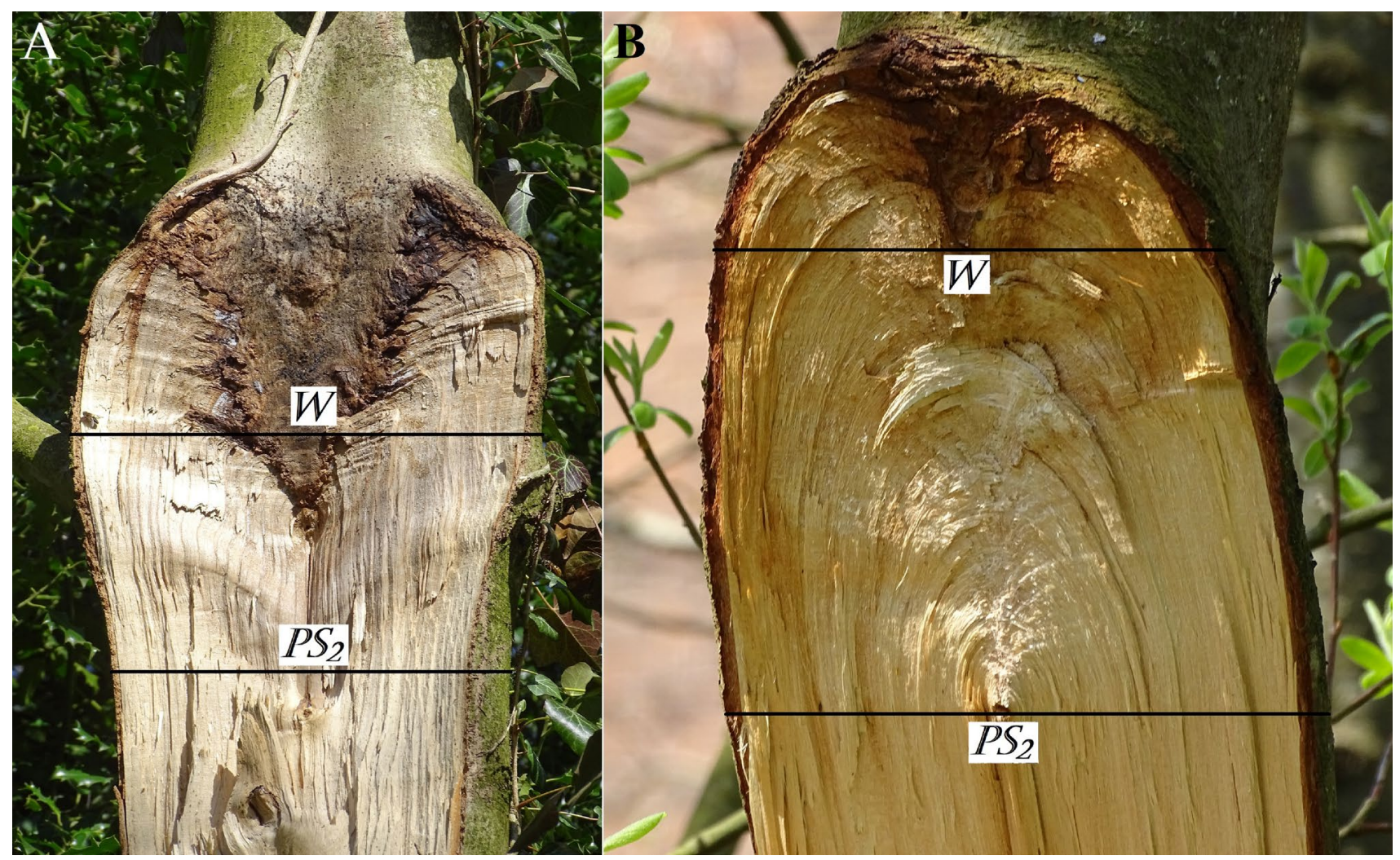

Fig. 7 Two examples of the 110 images of failed bark-included branch junctions illustrating how the 'bulge ratio' for each specimen was calculated by dividing the maximum width of the stem where

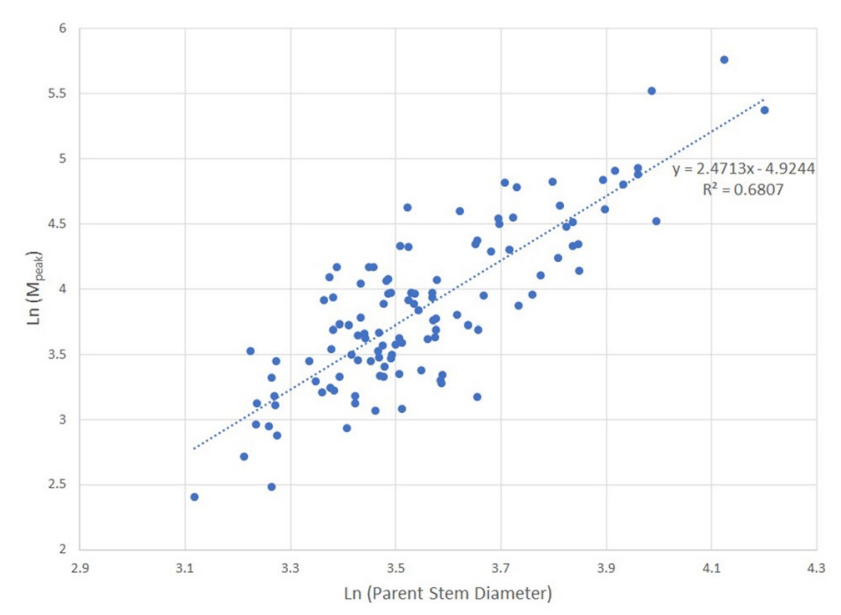

Fig. 8 Plot of log of bending moment against log of averaged parent stem diameter (using the formula $\left(\mathrm{PS}_{1}+\mathrm{PS}_{2}+\mathrm{PS}_{2}\right) / 3$ ). The equation defining the linear relationship provided here was used to normalise the bending moments of samples for their relative size, allowing for analysis of other factors that would explain variations in maximal bending moment the bark was included $(W)$ with the width of the parent stem below it $\left(\mathrm{PS}_{2}\right)$. Image A shows a specimen with a bulge ratio of $+18.5 \%$ and Image B shows a specimen with a bulge ratio of $-12.3 \%$

The observed modes of failure of the tested branch junctions (Slater and Ennos 2013) identified that 29 specimens exhibited Type I mode of failure, 86 specimens exhibited Type II mode of failure, and one specimen failed along the length of its smaller branch B, rather than at the junction. Type II mode of failure was associated with a significantly higher maximal bending moment $\left(M_{\text {peak }}=64.4 \mathrm{Nm} \pm 23.3\right.$ SD) than those which exhibited a Type I mode of failure (54.5 $\mathrm{Nm} \pm 23.2 \mathrm{SD})$, as confirmed by a one-way ANOVA $\left(F_{1,113}=4.05 ; p=0.047\right)$ and post hoc Tukey test.

A further one-way ANOVA identified significant differences in the maximum bending moments (when normalised for specimen size) for the types of branch junctions tested (Fig. 9). The peak bending moments experienced by the specimens with wide bark inclusions were on average only $54 \%$ of the control specimens and $88.7 \%$ that of the cup unions tested (when normalised for specimen size), highlighting them as substantially weaker. 
Fig. 9 Boxplot of maximal bending moment (normalised for specimen size) for the four types of branch junction tested $(n=115)$. Letters set above the plots denote heterogeneity of group means at the 5\% significance level, as determined by a one-way ANOVA $\left(F_{3,111}=26.36 ; p<0.001\right)$ and post hoc Tukey test

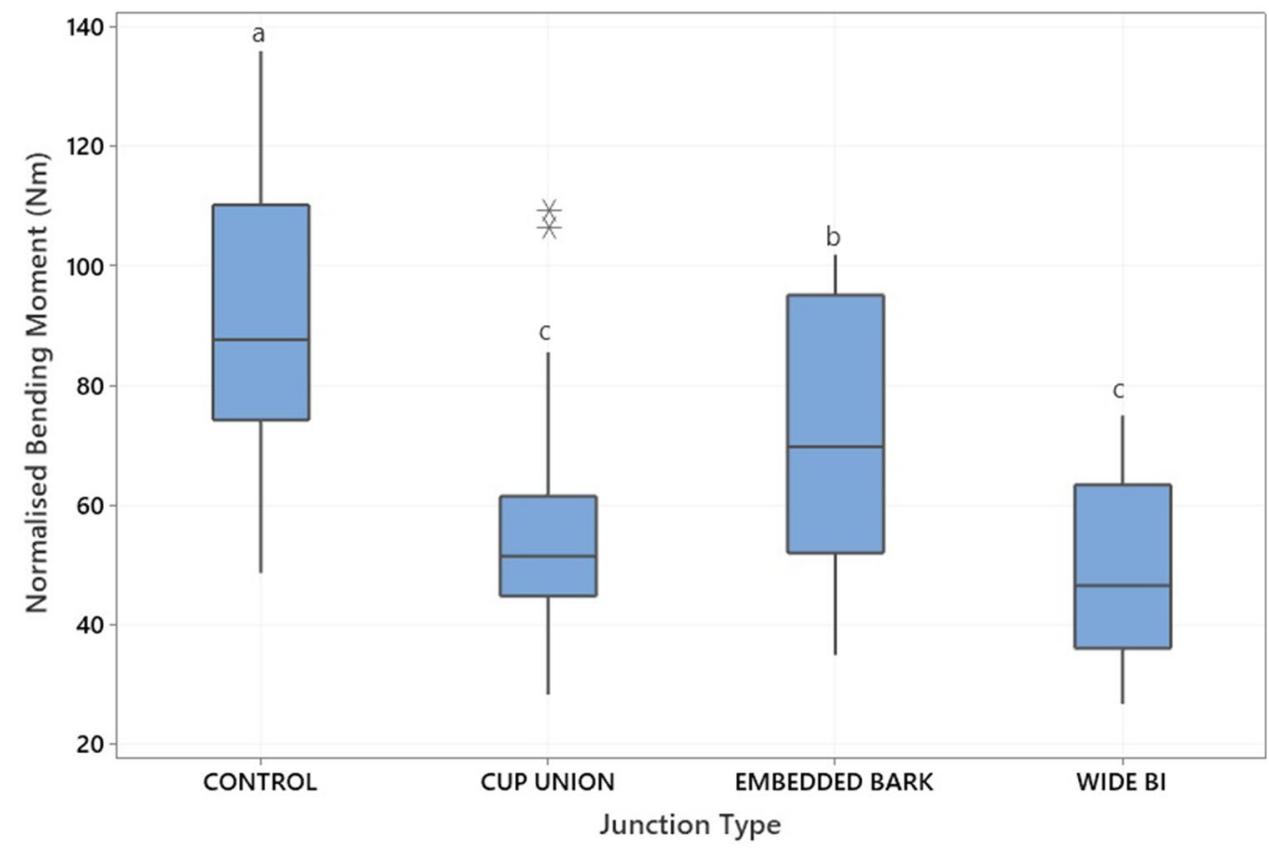

Table 1 Relationships between branch junction type, extent of bulging and peak bending stress for the 115 samples of hazel subject to tensile testing (excluding from analysis one branch failure and one cracked branch junction)

\begin{tabular}{lllll}
\hline Branch junction type & Sample size $(n)$ & Mean bulge ratio $\pm \mathrm{SD}$ & $\begin{array}{l}\text { Mean normalised peak bend- } \\
\text { ing moment } \pm \mathrm{SD}\end{array}$ & $\begin{array}{l}\text { Correlation between bulg- } \\
\text { ing ratio and peak bending } \\
\text { moment }\end{array}$ \\
\hline Control & 22 & $10.6 \% \pm 5.9 \% \mathrm{SD}^{a}$ & $90.0 \mathrm{Nm} \pm 23.0 \mathrm{SD}^{a}$ & $r=0.380 ; p=0.081$ \\
Embedded bark & 14 & $17.8 \% \pm 10.1 \% \mathrm{SD}^{a b}$ & $70.8 \mathrm{Nm} \pm 22.0 \mathrm{SD}^{b}$ & $r=0.014 ; p=0.962$ \\
Cup union & 49 & $25.4 \% \pm 12.5 \% \mathrm{SD}^{b c}$ & $54.8 \mathrm{Nm} \pm 17.0 \mathrm{SD}^{c}$ & $r=0.116 ; p=0.427$ \\
Wide bark inclusion & 30 & $32.4 \% \pm 14.7 \% \mathrm{SD}^{c}$ & $48.6 \mathrm{Nm} \pm 13.9 \mathrm{SD}^{c}$ & $r=0.228 ; p=0.234$ \\
ALL & 115 & $23.5 \% \pm 14.0 \% \mathrm{SD}$ & $61.8 \mathrm{Nm} \pm 23.5 \mathrm{SD}$ & $r=-0.268 ; p=0.00378$ \\
\hline
\end{tabular}

Different italicized letters in columns 3 and 4 identify significant heterogeneity in mean values across the four branch junction types

\section{The effects of bulging on maximal bending moment}

The mean bulging ratio of specimens was $23.5 \% \pm 14 \% \mathrm{SD}$, with a range between 0 and $82 \%$. A Kruskal-Wallis and post hoc Mood's median test identified there were significant differences in bulging with the four types of branch junction tested, as identified in Table $1\left(H_{3}=43.94 ; P<0.001\right)$. There was no significant correlation between the proportional size of the bulge around a branch junction and its maximal bending moment, for any of the four types of branch junction tested but which all showed a positive trend (i.e. higher bending moment for a higher bulging ratio) (Table 1). Combining all groups gave a significant negative correlation as control and embedded bark specimens had lower bulging ratios and higher mean bending moments when compared with cup unions and wide bark inclusions (Table 1).

\section{Wood density testing}

The mean wood density of the cuboids extracted from the axils of branch junctions in control specimens was $728 \mathrm{~kg} \mathrm{~m}^{-3} \pm 49$ Standard Deviation (SD) and in barkincluded specimens (embedded, cup unions and wide barkincluded junctions), the mean value was $733 \mathrm{~kg} \mathrm{~m}^{-3} \pm 44$ SD. Both mean values were higher than cuboids cut from the adjacent stems $\left(556 \mathrm{~kg} \mathrm{~m}^{-3} \pm 39 \mathrm{SD}\right)$ and this was found to be a statistically significant difference using a paired $t$ test $\left(t_{116}=46.85 ; p<0.001\right)$. All the cuboids taken from the 
axils of the branch junctions were denser than their paired samples from the stem, with the range being between 13.4 and $54 \%$ denser.

\section{Modelling the load-bearing capacity of bark-included branch junctions}

A bivariate regression analysis was used to determine which measured parameters of the tested bark-included branch junctions (cup unions and wide bark-included junctions only) were significant predictors of their maximal bending moment. The best regression model was based on a Box-Cox transformation, incorporating the factors of parent stem diameter, junction type, diameter ratio and bulging ratio to predict maximal bending moment $\left(M_{\text {peak }}\right)$ $\left(F_{4,74}=110.4 ; R^{2}=85.65 \% ; p<0.001\right)$. The equation from this model was: (i.e. a high diameter ratio). A greater extent of bulging was related to an increased bending moment and taking this factor into account improved the model's goodness-of-fit (from 10.56 to 9.91), despite the factor being statistically non-significant.

Where bark inclusion ratio was used, this had a very similar effect to the model as 'Junction Type', with a significant negative contribution to bending moment when a higher proportion of included bark was present at the junction's apex. However, as the type of bark inclusion and the ratio of bark inclusion at the apex were not independent variables, it was not considered valid to include both factors in a regression model. Stepwise regression removed wood density from all combinational models as a non-significant predictive factor.

$\ln \left(M_{\text {peak }}\right)=$ Constant $+0.067 \mathrm{PS}_{2}+1.182$ Diameterratio +0.306 Bulgingratio,

with the constant for cup unions being 0.353 and the constant for wide bark inclusions being 0.106. The model identified the significant influence of parent stem diameter $\left(F_{4,74}=405.58 ; p<0.001\right)$, junction type $\left(F_{4,74}=16.62\right.$; $p<0.001)$, diameter ratio $\left(F_{4,74}=23.96 ; p<0.001\right)$ but the bulging ratio was a non-significant factor $\left(F_{4,74}=2.12\right.$; $p=0.149$ ). The model implies a higher bending moment for junctions with a larger parent stem (a proxy for junction size), a higher bending moment for cup unions compared to wide bark inclusions and a higher bending moment for junctions where the two arising branches have a similar diameter

\section{Post-failure photographic analysis}

The frequency of failures at different extents of bulging is illustrated in Fig. 10, using gradations of $5 \%$ of the bulge ratio to group specimens.

This analysis provided a failure ratio of 31:79 for failures relating to bulge ratios above $10 \%$ compared with those relating to those of $10 \%$ bulging ratio or lower. This was then compared with Slater's (2018a) finding of a frequency of 21:78 for the bulging ratios above $10 \%$ with those below $10 \%$ in unbraced bark included junctions surveyed in a large
Fig. 10 Histogram illustrating the frequency of failures in each increment of $5 \%$ of bulge ratio for photographs of branch junctions with included bark that had failed $(n=110)$. The trend line illustrates the moving average. The most frequently seen failures were ones with only a $5 \%$ bulge ratio or no discernible bulging at all

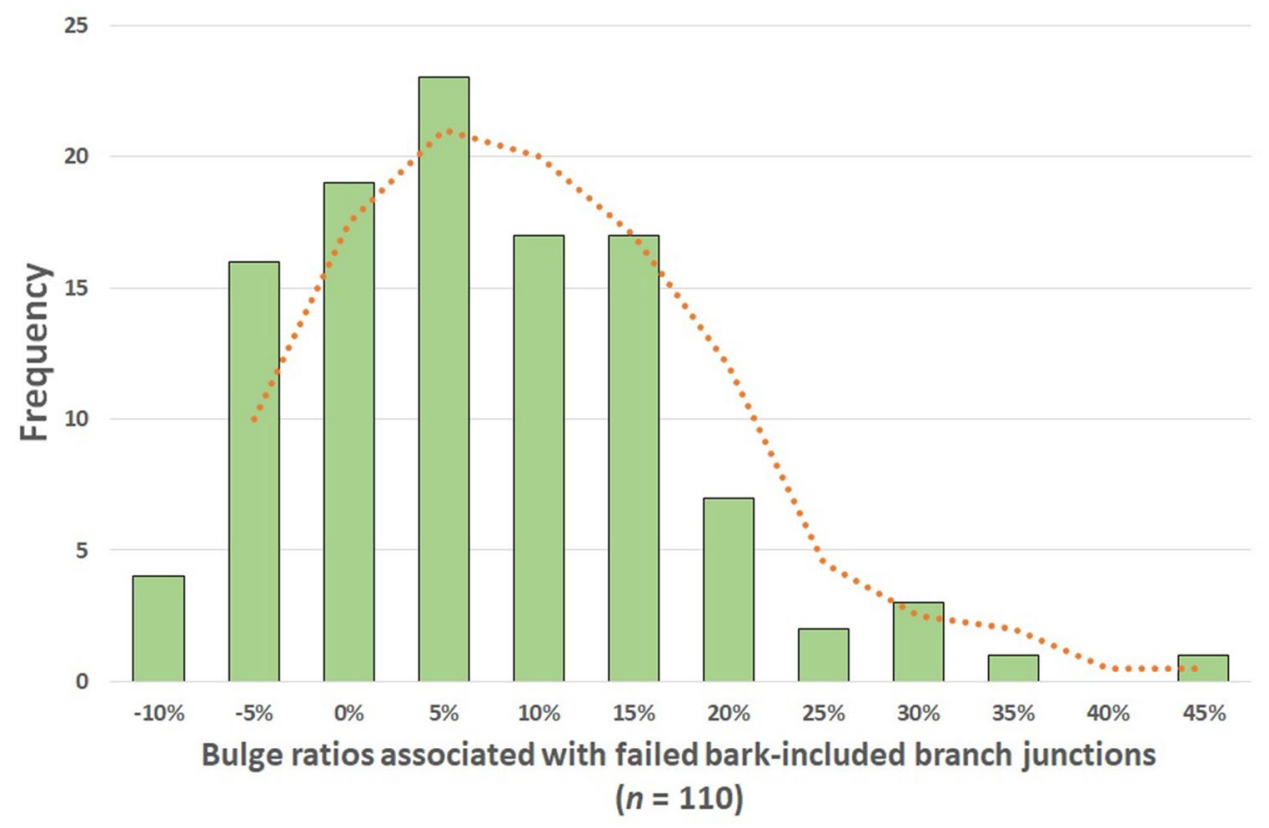


cohort of trees $(n=1998)$. This suggests that junctions above the $10 \%$ bulging ratio are slightly more prone to failure than those below this arbitrary $10 \%$ threshold as $28.18 \%$ of failures came from the larger bulges that represented $21.21 \%$ of the bark-included junctions in the cited cohort study; however, the majority of the failures above this threshold $(n=17)$ were only in the next banded category (i.e. $15 \%$ bulging ratio).

\section{Discussion}

The mean bending moments of the branch junctions by junction type were similar in distribution to the mean bending stresses by junction type reported by Slater and Ennos (2015a), except that the cup unions were not statistically differentiated from the wide bark inclusions. By deliberately selecting cup unions that exhibited noticeable bulging rather than a more rounded shape, this is likely to have resulted in a sample of cup unions that had a lower mean load-bearing capacity than a randomly-selected sample of cup unions. Hypothesis $H_{1}$ is rejected in this study.

Larger bulges exhibited by the tested branch junctions were a reliable indicator of the presence of included bark within them and the regression model identified a trend for larger bulging to confer greater strength. However, there was no significant statistical relationship between the diameter of the bulges and the maximal bending moment of these branch junctions, despite the wide range of bulge sizes being tested. This supports the logical argument that the bulges represent different degrees of compensation-for example, a large bark inclusion with only minor bulging around it will prove to be weaker than a cup union where secondary growth has compensated substantially for a minor internal defect. Such a cup union may exhibit only minor bulging externally due to continuing secondary growth of the whole component. This highlights that there are more complex relations between maximal bending moment and junction morphology and that Mattheck's hypothesis was not a useful predictor of outcomes in the tested sample. Hypothesis $\mathrm{H}_{2}$ is rejected in this study.

By combining the factors of parent stem diameter, junction type, diameter ratio and bulging ratio in the regression model, it was possible to predict $85.65 \%$ of the maximal bending moment of the bark-included samples tested (Eq. 2). A similar predictive model was generated by factoring in the extent of bark present at the apex of the branch junctions tested instead of the categories of junction types.

That the maximal bending moment was significantly increased in relation to a higher diameter ratio for the barkincluded junctions is a seemingly contrary finding to previous studies that estimated bending stresses for similar tensile tests of branch junctions using the method illustrated in
Fig. 5b (Gilman 2003; Kane 2007; Kane et al. 2008; Slater and Ennos 2015a). This former method would have a natural bias towards higher maximal bending stresses in junctions with one small-diameter branch attached to a much largerdiameter branch, as the maximal bending stress was calculated taking into account only the section modulus of the smaller-diameter branch. The results of this study found a different relationship that greater moment is needed to bend junctions where the two arising branches are of a similar diameter. This is a logical outcome when one considers that a larger-diameter branch will have a larger second moment of area.

This modelling leaves around $15 \%$ of the variation in maximal bending moment in these specimens unexplained. Observations of the fracture surfaces of these specimens found a wide range of surface roughness, from some specimens' fracture surfaces being relatively flat and much of the wood grain at the fracture surface aligned tangentially, to other specimens having very rough surfaces associated with teased out wood fibres and areas of the fracture surface where the wood grain was aligned radially and axially (Slater et al. 2014). It is most likely that wood grain orientation within the bulges formed around a bark inclusion may be an important factor in explaining variation in the loadbearing capacity of branch junctions. Note, however, that this is not a factor that could be observed externally by an arborist viewing an intact branch junction in a standing tree.

The wood of the tested samples was unequivocally denser within the axil of each branch junction than within the adjacent stem. Hypothesis $H_{3}$ is proven in this study. This testing suggests that all the branch junctions contained some axillary wood, including the bulged specimens, which matches the findings of previous research (Slater and Ennos 2015b). Wood density differences between specimens, however, did not prove to be a significant factor in modelling their loadbearing capacity, probably because wood density values were similar in all tested specimens. In this experiment, differences in the maximal bending moment related to other factors, such as diameter ratio, junction morphology and the position of any included bark.

The analysis of the post-failure photographs further supports the argument that the bulging is typically fulfilling the function of adding load-bearing capacity to a branch junction, not identifying it as substantially more likely to fail. A limitation to this aspect of the study was the paucity of data on the frequency of occurrence of different extents of bulging in the tree population overall. Further surveying and research could provide a larger sample and more detailed distribution of both bulging ratios in the population and their rates of failure. There is sufficient evidence, however, to reject hypothesis $H_{4}$.

Due to the high degree of association between natural bracing and the forming of bark-included junctions (Slater 
2018a), a logical picture emerges whereby those weakened bark-included junctions that are released from their natural bracing, either due to pruning or the loss of bracing branches, may start to produce additional wood (bulging) when opened up to movement and a new loading regime. Logically, such branch-included junctions are more likely to fail at the earlier stages of that bulging process, and less likely to fail at the latter stages (Figs. 3 and 10).

\section{Conclusion}

The findings of this study do not support Mattheck's hypothesis that it is the bark-included junctions with larger bulges that are weaker and more likely to fail. The observations and testing reported here imply that the extent of the defect that lies within the bulged part of a branch junction is important in predicting its load-bearing capacity and that it is more common to see the failure of bark-included branch junctions when there is limited to no bulging and the presence of a large proportion of included bark at the junction apex (Dunster et al. 2017), both of these features being observable for an arborist carrying out a visual assessment. A logical interpretation of these bulges is not as "secondary growth pushed to the side due to growth stresses building up inside compression forks" (Mattheck and Vorberg 1991; Mattheck and Breloer 1994) but as compensatory growth around a weak branch junction, stimulated to grow by mechanical loading and dynamic movement (Jaffe 1973). Testing these hypotheses and reporting the outcomes is important, as many arborists make tree felling and pruning decisions based on such published opinion.

Further research could usefully investigate the compensatory stages of this 'bulging' in a range of tree species. Such a study could discern sub-categories for bulged bark-included junctions, based upon testing their load-bearing capacity, expanding upon the division of such junctions between weaker 'wide bark inclusions' and stronger 'cup unions' made by Slater and Ennos (2015a). A detailed study of the anatomy of the wood formed in these bulges and looking for variations in their external morphology that relate to their load-bearing capacity, has the potential to explain more of the differences in biomechanical performance of these branch junctions.

Author contribution statement All sample collection, photography, mechanical testing, statistical analysis and the writing up of this study was carried out by the author.

Acknowledgements The author's thanks are given to Greenwood Twiggs for providing a source for the branch junctions tested in this experiment and to Paul Critchley of the University of Central Lancashire for providing access to the mechanical testing facilities for the experiment.

\section{Compliance with ethical standards}

Ethical statement The author is unaware of any conflicts of interest regarding this research. This research project was supported by Myerscough College, Lancashire, England and the University of Central Lancashire. No external funding was received. The branch junctions tested in this study were sourced from a local hazel coppice that was already planned for coppicing. The coppicing of hazel is a sustainable practice that provides many ecological, social and economic benefits to local communities.

Open Access This article is licensed under a Creative Commons Attribution 4.0 International License, which permits use, sharing, adaptation, distribution and reproduction in any medium or format, as long as you give appropriate credit to the original author(s) and the source, provide a link to the Creative Commons licence, and indicate if changes were made. The images or other third party material in this article are included in the article's Creative Commons licence, unless indicated otherwise in a credit line to the material. If material is not included in the article's Creative Commons licence and your intended use is not permitted by statutory regulation or exceeds the permitted use, you will need to obtain permission directly from the copyright holder. To view a copy of this licence, visit http://creativecommons.org/licenses/by/4.0/.

\section{References}

André JP (2000) Heterogeneous, branched, zigzag and circular vessels: unexpected but frequent forms of tracheary element files: description, localization, form. In: Savidge R, Barnett J, Napier $\mathrm{R}$ (eds) Cell and molecular biology of wood formation. Bios Scientific Publishers, Oxford, pp 387-395

Anten NPR, Schieving F (2010) The role of wood mass density and mechanical constraints in the economy of tree architecture. Am Nat 175:250-260

Dunster JA, Smiley ET, Matheny N, Lilly S (2017) Tree risk assessment manual, 2nd edn. International Society of Arboriculture, Champaign

Gartner BL (1995) Patterns of xylem variation within a tree and their hydraulic and mechanical consequences. In: Gartner BL (ed) Plant stems; physiological and functional morphology. Academic Press, New York

Gilman EF (2003) Branch to stem diameter affects strength of attachment. J Arboric 29:291-294

Hejnowicz Z, Kurcryńska EU (1987) Occurrence of circular vessels above axillary buds in stems of woody plants. Acta Soc Bot Pol 56:415-419

Hughes SW (2005) Archimedes revisited: a faster, better, cheaper method of accurately measuring the volume of small objects. Phys Educ 40(5):468-474

Jaffe MJ (1973) Thigmomorphogenesis: the response of plant growth and development to mechanical stimulation. Planta 114:143-157

Kane B (2007) Branch strength of Bradford pear (Pyrus calleryana var. 'Bradford'). Arboricult Urban For 33:283-291

Kane B, Farrell R, Zedaker SM, Loferski JR, Smith DW (2008) Failure mode and prediction of the strength of branch attachments. Arboricult Urban For 34:308-316

Kramer EM (1999) Observation of topological defects in the xylem of Populus deltoides and implications for the vascular cambium. $\mathbf{J}$ Theor Biol 200:223-230

Kramer EM, Borkowski MH (2004) Wood grain patterns at branch junctions: modelling and implications. Trees Struct Funct 18:493-500 
Larson PR, Isebrands JG (1978) Functional significance of the nodal constricted zone in Populus deltoides. Can J Bot 56:801-804

Lev-Yadun S, Aloni R (1990) Vascular differentiation in branch junctions of trees: circular patterns and functional significance. Trees Struct Funct 4:49-54

Lonsdale D (1999) Principles of tree hazard assessment and management. DETR, London

Matheny NP, Clark JR (1994) A photographic guide to the evaluation of hazard trees in urban areas. Urbana, ISA

Mattheck C (1998) Design in nature: learning from trees. Springer, Berlin

Mattheck C, Breloer H (1994) The body language of trees: a handbook for failure analysis. TSO, London

Mattheck C, Vorberg U (1991) The biomechanics of tree fork design. Botan Acta 104(5):399-404

Meadows D, Slater D (2019) Assessment of the bending strength of bark-included junctions in Crataegus monogyna Jacq. in the presence and absence of natural braces. Arboricult Urban For 46(3):211-228

Niklas KJ, Spatz H-C (2012) Plant physics. University of Chicago Press, Chicago

Ozden S, Slater D, Ennos AR (2017) Fracture properties of green wood formed within the forks of hazel (Corylus avellana $\mathrm{L}$ ). Trees Struct Funct 31(3):903-917

Pfisterer JA (2003) Towards a better understanding of tree failure: investigations into bending stresses of branch junctions and reiterates of European filbert (Corylus avellana L.) as a model organism. In: Second international symposium on plant health in urban horticulture, August 27-29, 2003 Berlin

Shigo AL (1985) How tree branches are attached to trunks. Can J Bot 63:1391-1401
Slater D (2016) Assessment of tree forks. Arboricultural Association, Stroud

Slater D (2018a) The association between natural braces and the development of bark-included junctions in trees. Arboricult $\mathrm{J}$ 40(1):16-38

Slater D (2018b) Natural bracing in trees: management recommendations. Arboricult J 40(2):106-133

Slater D, Ennos AR (2013) Determining the mechanical properties of hazel forks by testing their component parts. Trees Struct Funct 27:1515-1524

Slater D, Ennos AR (2015a) The level of occlusion of included bark affects the strength of bifurcations in hazel (Corylus avellana L.). Arboricult Urban For 41:194-207

Slater D, Ennos AR (2015b) Interlocking wood grain patterns provide improved wood strength properties in forks of hazel (Corylus avellana L.). Arboricult J 37:21-32

Slater D, Ennos AR (2016) An assessment of the ability of bifurcations of hazel (Corylus avellana L.) to remodel in response to bracing, drilling and splitting. Arboricult Urban For 42:355-370

Slater D, Bradley RS, Withers PJ, Ennos AR (2014) The anatomy and grain pattern in forks of hazel (Corylus avellana L.) and other tree species. Trees Struct Funct 28:1437-1448

Smiley ET (2003) Does included bark reduce the strength of co-dominant stems? J Arbor 29:104-106

Zimmermann MH (1978) Hydraulic architecture of some diffuse porous trees. Can J Bot 59:2286-2295

Publisher's Note Springer Nature remains neutral with regard to jurisdictional claims in published maps and institutional affiliations. 